\title{
Comparative analysis of non-classically secreted proteins in Botrytis cinerea and symbiotic fungus Laccaria bicolor
} Preti Jain*, Gopi K Podila and Maria R Davis

\author{
Address: Department of Biological Sciences, University of Alabama in Huntsville, Huntsville, Alabama, 35899, USA \\ Email: Preti Jain* - jainp@uah.edu \\ * Corresponding author
}

from Fourth International Society for Computational Biology (ISCB) Student Council Symposium

Toronto, Canada. 18 July 2008

Published: 30 October 2008

BMC Bioinformatics 2008, 9(Suppl I0):O3 doi:I0.I I86/I47I-2I05-9-SI0-O3

This abstract is available from: http://www.biomedcentral.com/I47I-2 I05/9/SI0/O3

(C) 2008 Jain et al; licensee BioMed Central Ltd

\section{Background}

Unconventional protein secretion, also known as nonclassical protein export or endoplasmic reticulum (ER)/ Golgi-independent protein secretion, from eukaryotic cells was discovered more than a decade ago, yet, the molecular mechanisms and machinery components that mediate this process remain unknown [1]. Many of the current experimental methods of analysis fail to detect proteins accumulated in low amounts due to the presence of more abundant factors in the secretions. We are using bioinformatics to analyze the genomes of Botrytis cinerea BO5.10 and Laccaria bicolor, along with the genomes of 5 other ascomycetes and basidiomycetes, in order to predict non-classically secreted proteins (NCSP). Extracellular secreted proteins are classified as either conventional or non-conventional in their secretion mechanisms. Several lines of evidence indicate that various kinds of mechanistically distinct non-classical export routes may exist. The N-terminus of a NCSP although uncleaved exits the cell under a variety of alternate transport mechanisms [2].

\section{Materials and methods}

In this study, we used computational approaches to identify novel proteins of the non-conventional secretome in 8 fungal genomes. The sequences were downloaded from the Broad Institute http://www.broad.mit.edu/ and the DOE Joint Genome Project http://www.jgi.doe.gov/. The SecretomeP program http://www.cbs.dtu.dk/services/ SecretomeP/ was used for the prediction of non-classical secreted proteins. Proteins having an NN score $>0.5$ were retained. The flow chart of the method used is shown as Figure 1.

\section{Q-PCR}

The extracellular proteins of B. cinerea, L. bicolor and $S$. sclerotiorum were further tested using QPCR methods on RNA isolated from fungal organisms undergoing fungal/ plant interactions verses normal conditions.

\section{Results}

NCSP were classified into 6 major categories. Carbohydrate metabolism and transport constituted $25 \%$ of all predicted proteins. The detailed distribution of all predicted proteins is shown in Figure 2. Computational results are experimentally confirmed by LC-MS/MS for 6 proteins in B. cinerea and 16 in Phanerochaete chrysosporium. Lectin-type proteins were uniquely represented in Laccaria and Botrytis profiles while, approximately $90 \%$ of proteases were found to be enriched in the basidiomycetes, $L$. bicolor and $P$. chrysosporium. It was observed by whole genome arrays that two fungal lectins are up-regulated and 4 glyoxal oxidases are down-regulated in mycorrhizal conditions (L. bicolor) and may be correlated to external signals from the plant that control non-classical secretion. It suggests that these proteins bypass glycosylation and may provide a means for modulating developmental processes of both the fungus and its plant host. Glycosyl hydrolases are critical for the hydrolysis of plant derived biomass [3]. These are the most represented family of proteins in plant interacting genomes via our analy- 


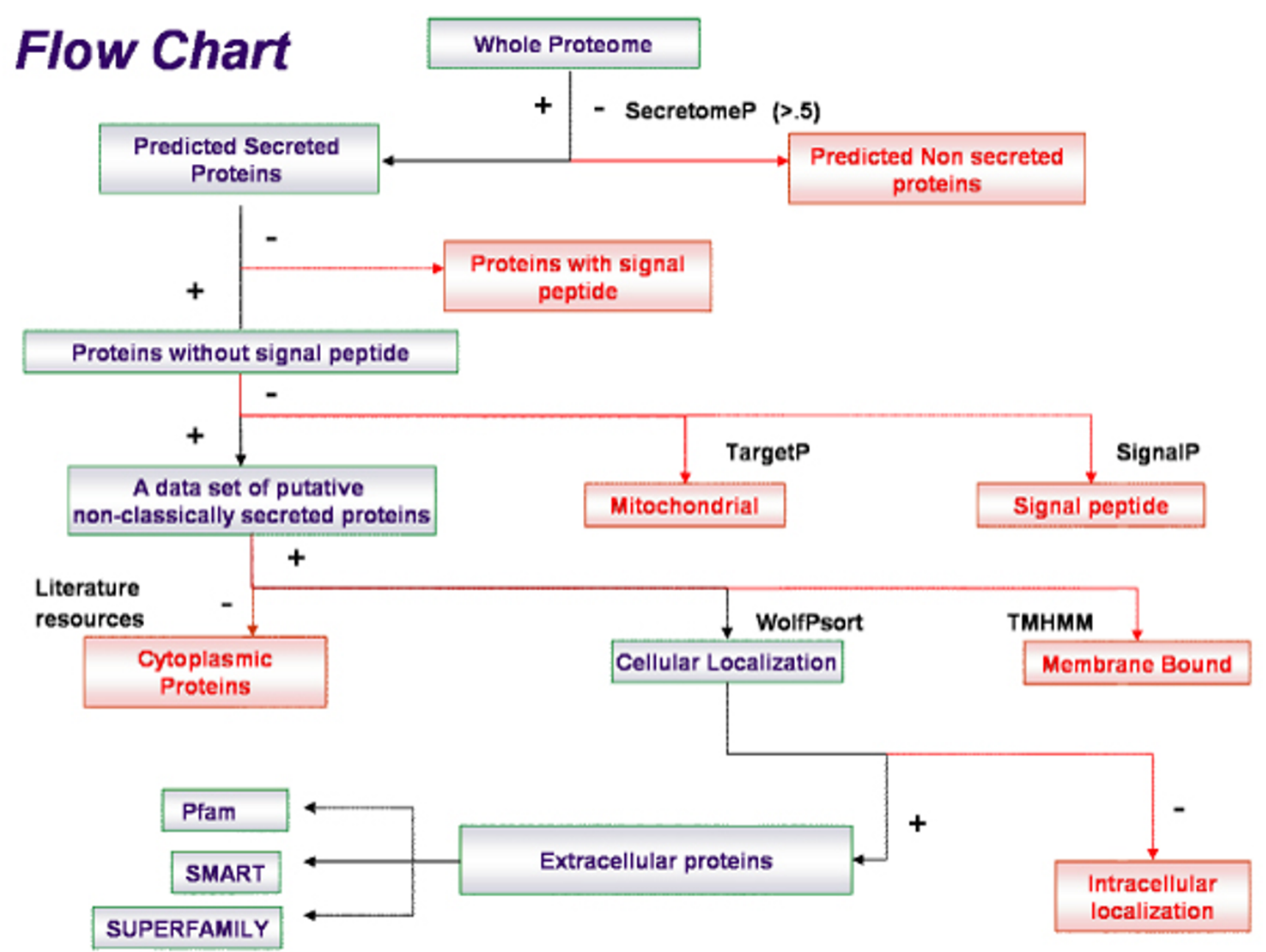

Figure I

sis. It is also suggested that the enhancement of nonclassical export might be caused by cellular stress, which results in increased heat shock protein expression. A possible physiological function for nonclassical export is to remove toxic proteins from the cytoplasm. It may

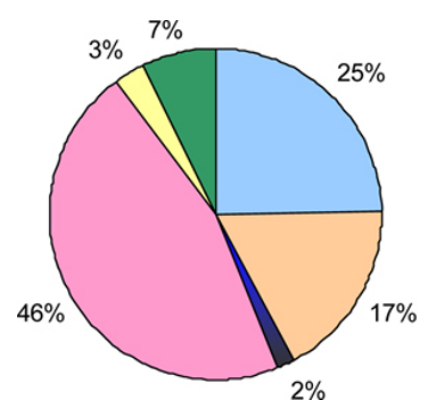

$\square$ Carbohydrate metabolism
and Transport
$\square$ Other Metabolism related
proteins
$\square$ lectins
$\square$ Miscellaneous
$\square$ hydrolase
$\square$ Peptidase and Proteolytic

Figure 2 also participate in detoxification mechanisms. This type of bioinformatic identification of putative NCSP offers a reliable methodology to overcome the limitation of current experimental methods that limit the comprehensive identification of (unexpressed/under-detected) proteins in a known genome sequence.

\section{References}

I. Nickel W: The mystery of nonclassical protein secretion. A current view on cargo proteins and potential export routes. EurJ Biochem 2003, 270:2109-2119.

2. Prudovsky I, Tarantini F, Landriscina M, Neivandt D, Soldi R, Kirov A Small D, Kathir KM, Rajalingam D, Kumar TK: Secretion Without Golgi. J Cell Biochem 2008, I03:1327-1343.

3. Bonfim SM, Cruz AH, Jesuino RS, Ulhoa CJ, Molinari-Madlum EE, Soares CM, Pereira M: Chitinase from Paracoccidioides brasiliensis : molecular cloning, structural, phylogenetic, expression and activity analysis. FEMS Immunology \& Medical Microbiology 2006, 46:269-283. 